ARTICLE

\title{
The validity of Rodrik's conclusion on real exchange rate and economic growth: factor priority evidence from feature selection approach
}

\author{
Mehdi Seraj (10 ${ }^{1 凶}$, Pejman Bahramian², Abdulkareem Alhassan (10 ${ }^{3}$ \& Rasool Dehghanzadeh Shahabad ${ }^{3}$
}

\begin{abstract}
The undesirable effect of poor exchange rate policy on economic growth has been firmly established in the literature using various parametric methods of econometric techniques. However, less is known about the prioritization of the exchange rate as a determinant of economic growth using a nonparametric approach. Thus, this study introduced machining learning approach (feature selection, particle swarm optimization-PSO, and genetic algorithm-GA techniques) to evaluate the relative primacy of the exchange rate for sustainable economic growth in Germany, South Africa, and Slovakia using Rodrik model with time series data from 1990 to 2016 . The study reveals that GDP per capita is the most crucial variable for economic growth in Germany and South Africa whereas, in Slovakia, the real exchange rate takes precedence over all other determinants of economic growth. That is, exchange rate takes precedence over other factors as a determinant of economic growth in an economy (Slovakia) with the high rate of trade openness while income per capita is the most important determinant of economic growth in economies (Germany and South Africa) with a relatively lower rate of trade openness. This partly supports Rodrik's conclusion. We, therefore, recommend that highly opened economies should focus on viable exchange rate policies, such as undervaluation of currency to enhance sustained economic growth. On the other hand, relatively less open economies should focus on policies that improve income per capita rather than exchange rate policies.
\end{abstract}

\footnotetext{
${ }^{1}$ Near East University, Nicosia, North Cyprus, Turkey. ${ }^{2}$ Queens University, Kingston, Ontario, Canada. ${ }^{3}$ Eastern Mediterranean University, Famagusta, North Cyprus, Turkey. ${ }^{\circledR}$ email: mehdi.seraj@neu.edu.tr
} 


\section{Introduction}

he empirical literature has firmly established the negative effect of poor exchange rate policy on economic growth and development. However, little or no attention has been paid to the relative importance of the exchange rate as a determinant of economic growth. Meanwhile, factor priority is vital for the examination of the determinants of economic growth.

Meanwhile, the need for desirable exchange rate policies become one of the major macroeconomic objectives of all countries. Hence, empirical studies have focused on the effect of undervaluation and/or overvaluation of currencies on sustainable economic growth. For instance, Rodrik (2008) found that exchange rate undervaluation stimulates economic growth in developing countries. He also claimed that his findings are robust for different measures of the exchange rate and different estimation techniques. The critical questions needed to be answered about the findings of Rodrik's work are; how relevant is undervaluation (or other measures of the exchange rate) as a stimulant of economic growth? Would the findings be valid for all forms of the functional relationship between the exchange rate and economic growth? Does the priority of the exchange rate remain the same for economic growth in developed, emerging (such as BRICS) and underdeveloped countries? To the best of the knowledge of the authors, all these questions are still begging for answers despite the plethora of studies regarding the effect of the exchange rate on economic growth.

Earlier, Easterly (2003) in his cynical studies of the crosscountry growth literature, argued that high overvaluation would have a negative impact on economic growth which has been consistently intensified by economic and political instability. $\mathrm{He}$ also observed that the problem of overvaluation of currencies has been related to foreign currency insufficiency, unsustainable current account, fluctuation in macroeconomics dynamics imbalance in payments and deficit. These problems in one way or the other have a damaging impact on economic growth.

Since then, there have been numerous studies on the relationship between the real exchange rate and economic growth. Some of the studies focus on the impact of exchange rate regime on economic growth (see Levy-Yeyati and Sturzenegger, 2003; Harms and Kretschmann, 2009; Sokolov et al., 2011; Ma and McCauley, 2011; De Vita and Kyaw, 2011; Benhima, 2012); while others focus on the linkages between real exchange rate and economic growth (see Tharakan, 1999; Rodrik, 2008; Tarawalie, 2010; Abida, 2011; Elbadawi et al., 2012; Glüzmann et al., 2012; and Vieira et al., 2013). Most of these studies focus on finding the relationship between the variables of interest for various economies using different econometric techniques. The estimation techniques employed in most of the studies are the parametric approaches including both dynamic and system generalized method of moments (GMM) and other parametric estimation techniques.

However, no paper exists on the relationship between real exchange rate and economic growth that focuses on the prioritization of the impact of exchange rate measures on economic growth using the nonparametric technique. In other words, to the best of the authors' knowledge, no researcher in the field of economics has ever used these machining learning techniques to investigate the relationship between real exchange rate and economic growth. It is on this premise that we employ the machining learning approach of particle swarm optimization (PSO), genetic algorithm (GA), and feature selection to evaluate the validity of Rodrik's findings for Germany, Slovakia, and South Africa, as developed, developing and emerging economies, respectively.

Therefore, the contribution of this study is twofold: First, evaluate the validity of the findings of Rodrik's work in developed, developing, and emerging economies using the nonparametric estimation techniques of machining learning approach. Secondly, to determine the optimal model between two major variants of machining learning approach (PSO and GA techniques) for countries under observation. These are a great addition to the literature of exchange rate-growth relationships.

The layout of the paper is scheduled as follows: in section "Data and variables" we discuss the data and variables of interest. In section "Methodology" we discuss in detail the methodology employed (machining learning approach of PSO, GA, and feature selection). Section "Results and discussions" contains the results and empirical findings. Finally, we conclude in section "Conclusion".

\section{Data and variables}

Our empirical investigation uses annual data for three selected countries, namely Germany, Slovakia, and South Africa. Thus, this study introduced machining learning approach (PSO, GA, and feature selection techniques) to evaluate the relative primacy of the exchange rate among other factors for sustainable economic growth in Germany, South Africa, and Slovakia. The selection of these countries has been done so to represent countries with different economic structures. Germany is a major developed country with a flexible exchange rate regime and with huge trade surpluses. More specifically, it is the strongest economy in Europe and the fourth strongest economy in the world in nominal terms. On the other hand, both South Africa is a middleincome, developing country with also floating exchange rate regimes. However, South Africa is the only BRICS member and second-largest economy and by far the largest GDP per capita in sub-Saharan Africa. On the other hand, Slovakia is a high-income country, which became a European Union member in 2004 and adopted the Euro in 2009. It recorded a 10.4\% GDP growth between 2000 and 2008, the highest economic growth in Europe during the period. It is grown at a higher rate and more opened than the German economy. As a result, it is called the Talta Tiger. These significant dynamics of the Slovakian economy informed its choice in this study.

The variables under observation are GDP growth proxy for economic growth, undervaluation as a proxy for real exchange rate and GDP per capita, as specified and use in the Rodrik model. We obtained all data from the World Bank Database 2016 (online) over the period of 1990-2016. The variables are transformed into their natural logarithm to harmonize the units of measurement and avoid potential heteroscedasticity.

\section{Methodology}

In this section, we discuss the techniques of the machining learning approach. The discussion is important because of the relative novelty of the techniques in the field of Economics.

Rodrik model. Rodrik (2008) considers the maximum of 188 countries and 11, five years periods from 1950 to 1954 till 2000-2004. The estimation of the relationship between growth and RER undervaluation is following from:

$$
\text { Growth }_{i t}=\alpha+\beta \operatorname{lnRGDP} i t-1+\delta \ln \mathrm{UN}_{i t}+f_{i}+f_{t}+\mu_{i t}
$$

where annual GDP growth is the dependent variable, RGDP is the initial income per capita, $f_{i}$ and $f_{t}$ are the full set of country dummies, and the UN is the index of undervaluation. He used the Balassa-Samuelson effect to calculate the undervaluation. General agreement has been made regarding the testing of external and internal Balassa-Samuelson effects with an intense reservation on the use of purchasing power parity (PPP) in the tradeable sector. The debate is ongoing regarding the alternative model among the 
international economists and possible refinement of the econometric methodology has been advocated.

$$
\ln \mathrm{UN}_{i t}=\operatorname{lnRER}_{i t}-\widehat{\ln \widehat{R E R}}{ }_{i t}
$$

where $\widehat{\mathrm{RER}}_{i t}$, is the predicted value-form of the following equation:

$$
\operatorname{lnRER}_{i t}=\alpha+\beta \operatorname{lnRGDP}{ }_{i t}+f_{t}+\mu_{i t}
$$

This estimated equation is the Balassa-Samuelson effect.

Machining learning approach. Recently, researchers, though mostly in engineering (see Liu et al., 2002; Ceylam and Ozturk, 2004; Yusup et al., 2012) and few in the field of applied economics (see Canyurt et al., 2005, 2006, 2008; Assareh et al., 2010; Amjadi et al., 2010; Yu et al., 2012; Saliminezhad and Lisaniler, 2018) have been carrying out research using machining learning approach. They found that the multilayer perceptron (MLPI outperforms linear regression. Several evolutionary approaches such as ACO, ABC, GA, PSO, and SA for optimization process parameters have been employed in machining learning due to the nonlinear nature of variables. The estimation of the exchange rate-growth relationship has been modeled using a different form of econometric equations. But none of these studies, including Rodrik (2008), considered the functional forms of their models. Often, relationships between variables are linear or nonlinear. Thus, it becomes paramount to first examine the functional forms of these models for better analysis, whether it is in a linear or non-linear form (see Bishop, 1986). Meanwhile, the nonlinear form of equations can be better handled by nonparametric techniques because the assumptions about the distribution of the variables are not needed. The result of the LM test for nonlinearity (popularly called Ramsey Reset Test) proposed by Ramsey $(1969,1974)$ conducted in this study shows that the variables employed are in nonlinear form. Thus, the PSO, GA, and feature selection techniques are used for the study. These nonparametric techniques do not need assumptions on the distribution of the variables. Also, the techniques check the priority of each variable and reduce the cost of estimation. The techniques are discussed in detail as follows.

Feature selection (multilayer artificial neural network-ANN). The purpose of feature selection is to process multifaceted data by discovering the suitable characteristics and get rid of the immaterial ones. Proper feature selection can cause a decrease in measurement costs and also provide a sound understanding of the genuine domain. Feature selection algorithms can be divided into four groups based on different selection strategies, which are embedded, hybrid, filter, and wrapper methods.

The embed techniques carry out feature selection through the process of training and obtaining model fitting of a particular mechanism concurrently. Rakotomamonjy (2003) in his analysis using SVM-based criteria to choose between relevant variables while discarding the irrelevant ones. This choice was based on SVM iterative to execute feature selection. The wrapper techniques harmonize a classifier such as SVM proposed by Bradley and Mangasarian (1998) LDA by Tang et al. (2014), KNN by Prasartvit et al. (2013) to choose between a set of features that possess the most discerning power. Other techniques of wrapper could be any combination of a particular given classifier and search strategy.

The filter techniques independently evaluate the important feature by studying the features of training data through specific statistical method and present the feature selection process of any classifier (Hybrid techniques, on the other hand, was proposed by seeing Uğuz, 2011; Ghamisi et al., 2014; and Xue et al., 2012). All the aforementioned techniques follow the pattern of the singleneuron model which is powerful in learning patterns but cannot learn all types of the pattern (Banerjee et al., 2003). Therefore, the multilayer ANN models are employed in this study. It has an intermediate hidden layer which enables it to learn all kinds of patterns and produce a good prediction. In the multilayer model, the inputs are first transformed into the hidden units whose outputs become the inputs of the output units (Banerjee et al., 2003). The output units finally produce outputs or predictions. The process is mathematically expressed as follows:

$$
\text { net }_{j}=b_{j}+\sum \gamma_{j i} x_{i}
$$

where net $t_{j}$ is the net value for the hidden unit $(j),\left(x_{i}\right)$ is the input of the unit $(i)$ and $\left(\gamma_{j i}\right)$ is a weight linking the input unit $(i)$ to the hidden unit $(j)$. The output of the hidden layer unit $(j)$, becomes

$$
G_{j}=G\left(\text { net }_{j}\right)
$$

Following the same process, the net value for the output unit $(h)$ is

$$
\text { net }_{h}=b_{h}+\sum \beta_{h j} G_{j}
$$

$\left(\beta_{h j}\right)$ is the weight linking the hidden unit $(j)$ to the output unit (h) while $\left(G_{j}\right)$ is the output of the hidden unit $(j)$, which serves as input for the output unit $(h)$. in that process, the final output of the output layer unit is

$$
F_{h}=f\left(b_{h}+\sum \beta_{h j} G\left(b_{j}+\sum \gamma_{j i} x_{i}\right)\right)
$$

Then, using the generalized delta rule, the weight adjustment process (learning) for each output layer takes the form

$$
\beta_{h j}(t+1)=\beta_{h j}(t)+\eta \bar{V}
$$

$(\eta)$ is the learning rate (conventionally $<1)$, and $(\nabla h j)$ is the gradient vector associated with the weight $\left(\beta_{h j}\right)$.

PSO techniques. Eberhart and Kennedy (1995) introduced PSO to explain the problem related to continuous optimization. According to Li et al. (2008), the swarm is made up of volumeless pieces with stochastic rates, each of which depicts a workable or realizable solution. This makes it possible for the algorithm to discover the optimal solution by moving the particles in the solution space.

$$
\begin{aligned}
v_{i d}(t+1) & =\omega v_{i d}(t)+c_{i} r_{i d}(t)\left[y_{i d}(t)-x_{i d}(t)\right] \\
& +c_{2} r_{2 d}(t)\left[\widehat{y}_{d}(t)-x_{i d}(t)\right]
\end{aligned}
$$

where $\omega$ is the inertia weight factor, $c_{1} c_{2}$ is acceleration constant, in general $r_{1 d}, r_{2 d}$ are random numbers in the range [0,1], $y$ is position based on Pbest; $\hat{y}$ is position based on Gbest, $v_{i d}$ is velocity of particle $i$ in dimension $d, x_{i d}$ is position of particle $i$ in dimension $d$.

Generally, $\omega$ is a function specified as

$$
\omega=\omega_{\max }-\frac{\omega_{\max }-\omega_{\min }}{\text { Iter }_{\max }} \times \text { Iter }
$$

where $\omega_{\max }, \omega_{\min }$ : Initial and final interties parameter weights, Iter $_{\max }$ : maximum iteration number, Iter: Current iteration number. As the velocity of a particle is determined, its position becomes

$$
x_{i d}(t+1)=x_{i d}(t)+v_{i d}(t+1)
$$

In this study, empirically, Eq. (8) will be

$$
\operatorname{EXR}_{i d}(t+1)=\operatorname{EXR}(t)+v_{i d}(t+1)
$$

where EXR is the exchange rate. Eq. (9) determines the position of the exchange rate as a determinant of economic growth. 
The PSO is applied in this study because of its numerous advantages. The application of PSO is quite easy and requires just a few lines of programming code. To implement these programming codes, complicated mathematical operators are not required. Thus, it is computationally reasonable with regard to both speed and memory requirements. Also, it produces robust and high-quality solutions for continuous nonlinear optimization problems within shorter estimation time. PSO combines the characteristics of both the evolution strategies (ES) and GA and it has more stable convergence features than other stochastic techniques. (see Zuperl et al., 2007; Phanthuna et al., 2013; Anand and Suganthi, 2020). Succinctly, we used this technique due to its advantage in multi-objective optimization, the ability to reduce the cost of estimation and also checks the priority of each variable via permutation and combination.

Genetic algorithm. The GA is an optimization forecasting model. GA are mathematical tools that use broad sorts of applications. GAs are optimization methods and random search control by natural genetics and evolution principles. According to Goldberg (1989), GA is adaptive in nature, involves robust search processes, efficient, uses a huge amount of implied parallelism and generates nearly related optimal solutions. It is mostly used in the field of engineering, where it is becoming more famous. However, GA is also used in energy demand estimation. It is basically used to optimize the weight of various demand equations by making use of available data as a proxy for economic indicators. GA is also used in optimizing weights of equations to enhance the estimation of energy projections for the future. Canyurt et al. (2005) use various economic indicators for Turkey to study natural gas, oil, energy demand for coal and future household's energy demand. Amjadi et al. (2010) used GA techniques based on certain economic indicators to estimate electricity needs for Iran. Assareh et al. (2010) also employed GA methods to evaluate for Iran, oil demand based on specific socio-economic indicators, using linear and exponential form of GA, while Ceylan and Ozturk (2004) and Haldenbilen and Ceylan (2005) in their respective study on transportation energy demand and total energy demand for Turkey using GA technique estimations.

GA encompasses selection, crossover, and mutation process for the selection of a member. A member is selected on the basis of its fitness which is measured by the probability as follows:

$$
p_{i}=f_{i} / \sum_{k=1}^{n} f_{k}
$$

where $P_{i}$ is the probability of the $i$ th member in the population. The members with the best fitness value can participate several times while those with worse fitness value are deleted.

\section{Results and discussion}

In this section, we report the findings from the machining iteration carried out on the dataset. To determine the most optimized model that could improve the Rodrik model, between PSO and GA machining estimation, we present the estimation results for PSO and GA in Table 1 from 1000 iteration. In Table 1, the PSO model for Germany shows that the PSO is appropriate for a developed economy like Germany because the standard error generated through the machining estimation of PSO is minimal 0.084536 while the standard error generated though the GA is 0.15645 . By comparing these results, we conclude that the PSO with optimization produced a better and reliable model for a developed economy like Germany.

The implication of this is that, for Germany as a developed country, improving the Rodrik model through the PSO is a better and preferred model when compared to the GA model.
Table 1 Result of the PSO and GA.

\begin{tabular}{llllll}
\multirow{2}{*}{ Country } & PSO & & & GA & \\
\cline { 2 - 3 } \cline { 5 - 6 } & Error mean & Error St.D. & & Error mean & Error St.D. \\
\hline Germany & -0.0048063 & 0.084636 & & -0.0036723 & 0.15645 \\
South Africa & 0.018604 & 0.09148 & & -0.000924 & 0.081297 \\
Slovakia & 0.20946 & 0.81139 & -0.15867 & 1.4759 \\
\hline Source: Authors' computation. & & & \\
\hline
\end{tabular}

Table 2 Result of feature selection.

\begin{tabular}{llll}
\multirow{2}{*}{ Country } & Feature selection & & \\
\cline { 2 - 4 } & Selected feature & Probability & Cost \\
\hline Germany & GDP per capita & 0.34 & 0.009 \\
South Africa & GDP per capita & 0.44 & 0.007 \\
Slovakia & Real exchange rate undervaluation & 0.47 & 1.02 \\
\hline Source: Authors' computation. & & \\
\hline
\end{tabular}

Based on the result obtained, in Table 2, the most relevant independent variable according to FS that influences economic growth in Germany is GDP per capita. The GDP per capita estimate obtained through the FS estimate is 0.34 is positive and statistically significant with the standard error of 0.009 . That is, GDP per capita has a direct impact on the economic growth of Germany. An increase in GDP per capita would increase economic growth by 0.34 . This implies that using Rodrik model for Germany, where he specified GDP per capita and undervaluation as a function of economic growth, GDP per capita play most influential impact on the economic growth of Germany, while undervaluation has no significant impact on economic growth, this is in support of Rodrik ${ }^{1}$ conclusion for developed countries. According to Rodrik, he argued that undervaluation of the real exchange rate is not a good policy measure for the government or policymakers in developed countries to embark upon in the quest for enhanced sustainable economic growth.

In the case of Slovakia, which is also a developed economy. Based on our result, we found that PSO is a preferred model when compared with the GA model for Slovakia. That is, the PSO with the optimization model produced a minimal standard error estimate of 0.81139 compared to the GA optimization standard error estimate of 1.4759. That is, for Slovakia, the PSO model is better and reliable for improving the Rodrik model than the GA model. We could not fit our model for a developing country of Slovakia based on a data problem. However, the selected feature (FS) for Slovakia is the real exchange rate. This implies that real exchange is directly related to economic growth. An increase in the real exchange rate would increase economic growth by 0.47 . By implication, GDP per capita does not have a huge influencing impact on the economic growth of Slovakia. The findings do not conform to Rodrik's (2008) findings that undervaluation does not stimulate economic growth in developed countries. The probable reason is the fact that Slovakia surpassed Germany in terms of trade openness, merchandise trade growth, and GDP growth over the years. For instance, the Slovakian economy grew at $4.1 \%$ with $11.6 \%$ growth in merchandised trade and trade openness of about $190 \%$ of the GDP in 2018 (UNCTAD, 2019). On the other hand, the trade openness of Germany was $87 \%$ of GDP with $7.8 \%$ growth in merchandised trade and 1.4\% economic growth in 2018.

For South Africa, both the PSO and GA models can improve the Rodrik model. The PSO estimate is 0.9148 , while that of GA is 
0.081297. This by implication means that the GA model performs better for an emerging economy of South Africa than the PSO model with optimization. Thus, we conclude that, though both models are appropriate in improving the Rodrik hypothesis for South Africa, the GA model would provide a more reliable and efficient result, when compared with the PSO coefficient estimate. The GA model provides the least standard error estimate than the PSO model. Based on this fact, the GA coefficient estimate is more efficient and reliable than that of the PSO model for South Africa.

Similar to Germany, the selected feature (FS) for South Africa is also GDP per capita with a positive statistically significant coefficient estimate of 0.44 and a standard error estimate of 0.007 . This also implies that GDP per capita has a direct impact on the economic growth of South Africa. An increase in GDP per capita would increase the economic growth of South Africa by 0.44 . Thus, using the Rodrik model for South Africa, GDP per capita is the most crucial variable and it has a significant impact on growth than undervaluation, which has no significant impact on economic growth. This does not support Rodrik's conclusion for developing countries (see the "Conclusion" section for explanation)

\section{Conclusion}

In his 2008 study, Rodrik stressed the importance of the relationship between the real exchange rate and economic growth to policymakers. He argued that the undervaluation of currency influences and stimulate economic growth, particularly for developing countries. Since then several studies have been carried out to analyze the relationship. However, all of these studies have used one parametric estimation of econometric techniques or another, but none have been able to investigate the relationship using the machining learning approach (nonparametric approach). To the author's best knowledge, the current study is the first to apply the machining learning techniques on this topic using time series analysis of developed and developing economies over the period of 1990-2016. We investigated the validity of undervaluation (that is, the higher rate of the real exchange rate) for developed and developing economies (Germany, South Africa, and Slovakia). Our findings confirm that the undervaluation of currency stimulates growth in Slovakia but does not significantly affect economic growth in Germany and South Africa. In the case of South Africa and Slovakia, the findings do not conform to Rodrik's (2008) findings. Slovakia is a developed country. Yet, undervaluation is the most important policy that stimulates economic growth in the country. On the other hand, our findings reveal that undervaluation does not stimulate economic growth in South Africa, a developing (emerging) economy. The plausible explanation for these opposite findings is the differences in the size and dynamics of tradable sectors of the countries. Although both are developed countries, Slovakia surpassed Germany in terms of trade openness, merchandise trade growth, and GDP growth over the years. For instance, the Slovakian economy grew at $4.1 \%$ with $11.6 \%$ growth in merchandised trade and trade openness of about 190\% of the GDP in 2018 (UNCTAD, 2019). On the other hand, the trade openness of Germany was $87 \%$ of GDP with $7.8 \%$ growth in merchandised trade and $1.4 \%$ economic growth in 2018 (UNCTAD, 2019). Since, Rodrik explained that the channel of transmission of the effect of the undervaluation is the tradable sector, the differences in the findings of Germany and Slovakia might be because of the wide gap in their growth and trade openness. Similarly, the tradable sector in South Africa is relatively underdeveloped with $0.8 \%$ GDP growth, 5.6\% growth in merchandised trade and trade openness of about $60 \%$ of GDP. The study also gives useful insight that will enable policymakers to achieve real exchange rate and economic growth targets for developed and developing economies. In short, this study concludes that the exchange rate takes precedence over other factors as a determinant of economic growth in developing and developed economies with the high rate of trade openness while income per capita is the most important determinant of economic growth at the lower rate of trade openness. We, therefore, recommend that highly opened economies should focus on viable exchange rate policies, such as undervaluation of currency to enhance sustained economic growth. On the other hand, relatively less open economies should focus on policies that improve income per capita rather than exchange rate policies.

\section{Data availability}

All data analyzed or generated are included in the paper.

Received: 17 December 2019; Accepted: 23 March 2020; Published online: 05 May 2020

\section{Notes}

1 For interested reader see Rodrik (2008).

\section{References}

Abida Z (2011) Real exchange rate misalignment and economic growth: an empirical study for the Maghreb countries. Zagreb Int Rev Econ Bus 14 (2):87-105

Amjadi MH, Nezamabadi-Pour H, Farsangi MM (2010) Estimation of electricity demand of Iran using two heuristic algorithms. Energy Convers Manag 51 (3):493-497

Anand A, Suganthi L (2020) Forecasting of electricity demand by hybrid ANN-PSO models. In: Khosrow-Pour M, Clarke S, Jennex ME, Anttiroiko A-V (eds) Deep learning and neural networks: concepts, methodologies, tools, and applications. IGI Global, p 865-882

Assareh E, Behrang MA, Assari MR, Ghanbarzadeh A (2010) Application of PSO (particle swarm optimization) and GA (genetic algorithm) techniques on demand estimation of oil in Iran. Energy 35(12):5223-5229

Banerjee A, Marcellino M, Masten I (2003) Leading indicators for Euro area inflation and GDP growth. CEPR Working Paper 3893

Benhima K (2012) Exchange rate volatility and productivity growth: the role of liability dollarization. Open Econ Rev 23(3):501-529

Bishop RED, Price WG, Wu Y (1986) A general linear hydroelasticity theory of floating structures moving in a seaway. Philosophical Transactions of the Royal Society of London. Series A, Math Phy Sci 316(1538):375-426

Bradley PS, Mangasarian OL, Street WN (1998) Feature selection via mathematical programming. INFORMS J Comput 10(2):209-217

Canyurt OE, Ozturk HK, Hepbasli A, Utlu Z (2005) Estimating the Turkish residential-commercial energy output based on genetic algorithm (GA) approaches. Energy Policy 33(8):1011-1019

Canyurt OE, Öztürk HK (2006) Three different applications of genetic algorithm (GA) search techniques on oil demand estimation. Energy conversion manag 47(18-19):3138-3148

Canyurt OE, Ozturk HK (2008) Application of genetic algorithm (GA) technique on demand estimation of fossil fuels in Turkey. Energy Policy 36 (7):2562-2569

Ceylan H, Ozturk HK (2004) Estimating energy demand of Turkey based on economic indicators using genetic algorithm approach. Energy Convers Manag 45(15-16):2525-2537

De Vita G, Kyaw KS (2011) Does the choice of exchange rate regime affect the economic growth of developing countries? J Dev Areas 45:135-153

Easterly W (2003) Can Foreign Aid Buy Growth? J Econ Perspect 17(3):23-48

Eberhart R, Kennedy J (1995) Particle swarm optimization. In Proceedings of the IEEE international conference on neural networks (Vol. 4, p 1942-1948) Citeseer

Elbadawi IA, Kaltani L, Soto R (2012) Aid, real exchange rate misalignment, and economic growth in Sub-Saharan Africa. World Dev 40(4):681-700

Ghamisi P, Couceiro MS, Benediktsson JA (2014) A novel feature selection approach based on FODPSO and SVM. IEEE Trans Geosci Remote Sens 53 (5):2935-2947

Glüzmann PA, Levy-Yeyati E, Sturzenegger F (2012) Exchange rate undervaluation and economic growth: Díaz Alejandro (1965) revisited. Econ Lett 117 (3):666-672

Goldberg DE (1989) Genetic algorithms in search. Optim Mach Learn, p 372, Addison-Wesley Longman Publishing Co., Inc. ISBN: 978-0-201-15767-3 
Harms P, Kretschmann M (2009) Words, deeds and outcomes: a survey on the growth effects of exchange rate regimes. J Econ Surv 23(1):139-164

Haldenbilen S, Ceylan H (2005) Genetic algorithm approach to estimate transport energy demand in Turkey. Energy policy 33(1):89-98

Levy-Yeyati E, Sturzenegger F (2003) To float or to fix: Evidence on the impact of exchange rate regimes on growth. Am Econ Rev 93(4):1173-1193

Li S, Wu X, Tan M (2008) Gene selection using hybrid particle swarm optimization and genetic algorithm. Soft Comput 12(11):1039-1048

Liu B, Lee W, Yu P, Li X (2002) Partially supervised classification of text documents. ICML

Ma G, McCauley RN (2011) The evolving renminbi regime and implications for Asian currency stability. J Jpn Int Econ 25(1):23-38

Phanthuna N, Jaturacherdchaiskul J, Lerdvanittip S, Auchariyamet S (2013) Application of particle swarm optimization for economic load dispatch and loss reduction. Resource 11:13

Prasartvit T, Banharnsakun A, Kaewkamnerdpong B, Achalakul T (2013) Reducing bioinformatics data dimension with ABC-kNN. Neurocomputing 116:367-381

Rodrik D (2008) The real exchange rate and economic growth. Brook Pap Econ Act 2008(2):365-412

Rakotomamonjy A (2003) Variable selection using SVM-based criteria. J Mach Learn Res 3:1357-1370

Ramsey JB (1969) Tests for specification errors in classical linear least-squares regression analysis. J R Stat Soc Ser B Methodol 31(2):350-371

Ramsey JB (1974) Classical model selection through specification error tests. Front Econom 1:13-47

Saliminezhad A, Lisaniler FG (2018) Validity of unbalanced growth theory and sectoral investment priorities in Indonesia: application of feature ranking methods. J Int Trade Econ Dev 27(5):521-540

Sokolov V, Lee BJ, Mark NC (2011) Linkages between exchange rate policy and macroeconomic performance. Pac Econ Rev 16(4):395-420

Tharakan J (1999) Economic growth and exchange rate uncertainty. Appl Econ 31 (3):347-358

Tang J, Alelyani S, Liu H (2014) Feature selection for classification: A review. Data classification: Algorithms and applications, 37

Tarawalie AB (2010) Real exchange rate behaviour and economic growth: evidence from Sierra Leone. South Afr J Econ Manag Sci 13(1):8-25

Uğuz H (2011) A two-stage feature selection method for text categorization by using information gain, principal component analysis and genetic algorithm. Knowl-Based Syst 24(7):1024-1032

Vieira FV, Holland M, da Silva CG, Bottecchia LC (2013) Growth and exchange rate volatility: a panel data analysis. Appl Econ 45(26):3733-3741

World Investment Report 2019
Xue B, Zhang M, Browne WN (2012) Particle swarm optimization for feature selection in classification: a multi-objective approach. IEEE Trans Cybern 43 (6):1656-1671

Yusup N, Zain AM, Hashim SZM (2012) Evolutionary techniques in optimizing machining parameters: Review and recent applications (2007-2011). Expert Syst Appl 39(10):9909-9927

Yu J, Wang M, Tao D (2012) Semisupervised multiview distance metric learning for cartoon synthesis. IEEE Trans Image Process 21(11):4636-4648

Zuperl U, Cus F, Gecevska V (2007) Optimization of the characteristic parameters in milling using the PSO evolution technique. Strojniski vestnik 53 (6):354-368

\section{Competing interests}

The authors declare no competing interests.

\section{Additional information}

Correspondence and requests for materials should be addressed to M.S.

Reprints and permission information is available at http://www.nature.com/reprints

Publisher's note Springer Nature remains neutral with regard to jurisdictional claims in published maps and institutional affiliations.

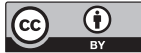

Open Access This article is licensed under a Creative Commons Attribution 4.0 International License, which permits use, sharing, adaptation, distribution and reproduction in any medium or format, as long as you give appropriate credit to the original author(s) and the source, provide a link to the Creative Commons license, and indicate if changes were made. The images or other third party material in this article are included in the article's Creative Commons license, unless indicated otherwise in a credit line to the material. If material is not included in the article's Creative Commons license and your intended use is not permitted by statutory regulation or exceeds the permitted use, you will need to obtain permission directly from the copyright holder. To view a copy of this license, visit http://creativecommons.org/ licenses/by/4.0\%

(C) The Author(s) 2020 